\title{
Knowledge And Practice Regarding Biomedical Waste in Different Levels of Government Health Care Facilities in West Bengal.
}

\author{
Dr.Baishakhi Paria ${ }^{1}$,Dr. Debasis Das ${ }^{2}$, \\ Assistant Professor,Department Of Community Medicine, Calcutta National Medical College, \\ Kolkata, West Bengal. \\ Associate Professor,Department Of Community Medicine, Medical College, Kolkata.West Bengal.
}

\begin{abstract}
:
Introduction:Biomedical wasteis a serious health hazard for health care providers,patients, and even togeneral public.Careless disposal of these waste can led to environmental pollution and spread of serious disease, among health care providers, patients and generalpeople.

Methodology:It was a descriptive, observational, cross-sectional, institution based study conducted one each of primary, secondary, tertiary care level government health institution of West Bengal to find out the awareness regarding bio-medical waste management, during May 2015 to August 2016. Data was collected by interview technique; simple percentages, ANOVAs were computed with help of Microsoft Excel 2007 software and SPSS software version 18.

Result:Most of health care institution had no provision for training regarding biomedical waste management.None provide prophylactic vaccination (pertaining to biomedical waste) to the health care providers.

Conclusion:Correct knowledge and practice regarding bio-medical waste management is essential to reduce the risk of transmission of disease. Awareness generation, regular training, vaccination, should be followed.

Keywords: Bio medical waste, Knowledge, Practice, West Bengal.
\end{abstract}

\section{Introduction}

Poor bio-medical waste management poses great risk to doctors, nurses, paramedical staffs, sanitary staffs, hospital maintenance personnel, patients, visitors to the hospitals, support service personnel, workers in waste disposal facilities, scavengers, generalpublic and more specifically to children. It is an occupational hazard to those who generate, collect, segregate, handle, package, store, transport, treat and dispose waste. ${ }^{1}$ Healthcare workers face the risk of infection due to blood or other liquid borne pathogens.

Doctors, nurses, healthcare auxiliaries, hospital maintenance personnel and patients in healthcare establishments are exposed to needle stick injuries. ${ }^{2}$ Skin injuries by sharp account for $66-95 \%$ of all occupational exposures to blood borne pathogens. ${ }^{3} \mathrm{~A}$ study conducted by Salelkar S among health care workers at a tertiary care hospital in Goa found that $34.8 \%$ had experienced a needle stick injury in last year. ${ }^{4}$ Sharma and Chauhan had shown that 10-18.5\% waste handlers suffered with injury in past 6 months in Govt. and nonGovt. hospitals of Agra and none reported to appropriate authorities. ${ }^{5}$ In Pakistan; prevalence of HCV in healthcare workers is $20 \%$ while the risk of infection after needle stick injury from Hepatitis B positive patient is $30 \%{ }^{6}$ Chia $\mathrm{H} \mathrm{P}$ et al observed that 171 needle stick injuries were experienced by 44 doctors in one year in a hospital in Singapore. ${ }^{7}$

Correct knowledge and practice regarding bio-medical waste management is essential to reduce the risk of transmission of disease and exposure to pathogens. Low level of knowledge was observed by DeoDeepali et al (in teaching hospitals) ${ }^{8}$; Saini et al (among paramedics in Delhi hospital) ${ }^{9}$; Waseem et al (in Srinagar) ${ }^{10}$; Kishore et al (Delhi hospital dentists in 2000) ${ }^{11}$; Joseph et al (Pondicherry hospital medical staff) ${ }^{12}$; Panditet al (auxiliary staff atSabarkantha District, Gujarat) ${ }^{13}$; Yadavannavar M C et al (non-teaching staff at Shri BM Patil Medical College and Hospital, Bijapur) ${ }^{14}$ and Sharma $\mathrm{S}$ et al (in three apex government hospitals of Agra, Uttar Pradesh $)^{5}$.

Sharma $\mathrm{S}$ et al also found that use of protective clothing was bare minimum among waste handlers and health care providers in Agra hospitals. ${ }^{5}$ Henry et al at two privately owned community hospitals in two suburbs of Minneapolis observed less than optimal levels of compliance of personal protective clothing among health care workers. ${ }^{15}$ Abdul et al had also made similar observations in 44 clinical laboratories of Karachi, Pakistan. ${ }^{16}$ In light of the above condition it was intended to assess the knowledge and practice regarding biomedical waste management among the health care providers in some Govt. institutions at various levels of health facilities in West Bengal, India because there is dearth of knowledge in this field of public health 
importance. Experiencing any needle stick injury and utilization of the personal protective equipment by the health care workers were also enquired.

\section{Methodology}

The present study was a descriptive, observational study with cross sectional multisite based design conducted in some government hospitals of West Bengal during May 2015 to August 2016 to assess the knowledge and practice regarding biomedical waste management among health care providers. The present study included one tertiary hospital (medical College Kolkata), six secondary level Government hospitals (three each of district hospitals and sub divisional hospitals) and three primary levels Government health care facilities (one rural hospital and two block primary health center). The hospitals were selected by simple random sampling. The three district hospitals (DH) were at Howrah (Howrah district), Chinsurah (Hooghly district) and Baharampur (Murshidabad district). The three sub divisional hospitals (SDH) were at Uluberia (Howrah), Srirampur (Hooghly) and Lalbag (Murshidabad). The rural hospital (RH/BPHC) was at Tarakeswar (Hooghly district) and the two block primary health centers were at Amta (Howrah) and Karnasubarna (Murshidabad).

Healthcare providers involved in biomedical waste management like doctors, nurses and technicians and biomedical waste handlers of tertiary and secondary and primary level health institutions were included as study population. Inclusion criteria were health care providers, who had given consent and technicians who were directly handling biomedical waste; junior doctors (interns, house staffs, PGT) were included to assess practiceregarding biomedical waste management in tertiary level health institution.

The parameters investigated were knowledge about disease transmitted by needle prick, colour coding of bags, collection,transportation, disposal of biomedical waste, use of protective gears, reporting after needle stick injury. To assess the knowledge and practice related to biomedical waste management, healthcare providers and biomedical waste handlers were interviewed with separate predesigned and pretested data collection form.

In tertiary level health care facility, $20 \%$ of doctors of each of the selected departments (surgery, gynaecology, orthopaedics and pathology) were interviewed. Similarly, 20\% of nursing staffs from each of departments of surgery, gynaecology, orthopaedics (Pathology was excluded because nursing staffs were not present),all technicians of pathology department and $20 \%$ of the total biomedical waste handlers of hospitals were also interviewed. Overall 48 doctors, 28 nursing staffs, 7 technicians and 22 biomedical waste handlers were interviewed. Among 48 doctors, 22 were interns, 3 were house staffs and 12 were post graduate trainees in different disciplines. To assess the practice related to biomedical waste management 37 doctors, 28 nursing staffs and 7 technicians and 22 biomedical waste handlers were interviewed.

In secondary level health care facilities, $20 \%$ of the doctors, $20 \%$ of the nursing staffs and $20 \%$ of the biomedical waste handlers and all technicians were interviewed from each of the six hospitals. Total number of doctors, nurses, technician and biomedical waste handlers taken were 55, 96, 26, and 21 respectively. All categories of health care providers were interviewed to assess the knowledge and practice related to biomedical waste management. Doctors were interviewed to assess the knowledge related issuesonly.

In primary level health care facilities, interviews of all doctors, nurses, technicians and biomedical waste handlers of each healthcare setting were conducted. Total number of doctors, nurses, technician and biomedical waste handlers included in the study were $14,35,6$, and 8 respectively. All categories of health care providers were interviewed to assess the knowledge and practice related biomedical waste management. Doctors were interviewed to assess the knowledge related issues only.

All total 117 doctors, 159 nurses and 39 technicians and 51 handlers were interviewed to assess the knowledge related biomedical waste management and 37 doctors, 159 nurses and 39 technicians and 51 handlers were interviewed to assess the practice related biomedical waste management.

To assess the knowledge and practice regarding biomedical waste management in health care providers, a simple scoring system was adopted. Simple percentages, ANOVA test and Pearson correlation coefficient was done using Microsoft Excel and software SPSS v18 package.

\section{Result}

It was observed that $89.7 \%$ of doctors and $77.3 \%$ of nurses gave correct responses regarding disease transmissionby biomedical waste while a minimum correct response was obtained by technicians (15.3\%) in this question. Regarding sharp collection, technicians gave maximum correct responses $(53.8 \%)$ whereas doctors responded minimum $(29.0 \%)$ in this question. Nursing staffs scored overall better total knowledge score than doctor and technicians. Regarding disease transmission by biomedical waste, PPE, vaccines and needle stick injury doctors scored better than nurses and technicians. Nursing staffs scored better in collection and disposal related questions.(Table 1)

Practice score was highest among doctors than nursing staffs and technicians.Doctors scored much better score than nurses and technicians regarding vaccination and use of personal protective equipment 
(PPE).No significant correlation was found in between knowledge and practice score of doctors, nurses, technicians.(Table 2)

There was significant difference of knowledge score and practice score obtained by doctors, nurses and technician on all aspects and collectively as per statistical test (ANOVA) applied. Upon Post hock test Tuckey Kramer test taking mean score of nurses as baseline, doctors were found to be getting higher knowledge score on disease transmission, PPE, vaccine and needle stick injury aspects but on collection, disposal and overall score they lack behind nurses. Technician obtained poorer scores compared to both doctors and nurses on all aspects of biomedical waste management and collective as well.Again doctors were found to be getting higher practice score on PPE, vaccine and collection, disposal and overall score. Technician obtained poorer scores compared to both doctors and nurses on all aspects of biomedical waste management and collective as well.(Table 3) technicians.

No significant correlation was found in between knowledge and practice score of doctors, nurses and

Maximum correct responses were obtained by handlers regarding colour coding of the bags and least correct responses were on needle stick injury followed by vaccination and method of transportation. Mean knowledge scores of handlers were more in colour coding of bags, (Table 4)

personal protective equipment and vaccination related issues and less in transportation related issues.

Mean practice scores of handlers were more in disposal and less in transportation related question. (Table 5)Knowledge and practice score of handlers showed significant correlation.

Among biomedical handlers 23(45.1\%) used gloves whereas 3(5.8\%) used both gloves and mask, $28(54.9 \%)$ used none of the protective equipment.Doctors, nurses and technicians and handlers sustained needle stick injury $9.2 \%, 38.1 \%, 11.8 \%$ and $40.7 \%$ respectively. Out of total injury only $10.4 \%$ reported to appropriate authority.

\section{Discussion}

A health care institution is a multidisciplinary system, which delivers medical care to the community. Hospital's waste poses a wide variety of health and safety hazards for patients and healthcare workers and also for people outside the hospitals area ${ }^{18}$.

\section{Knowledge and practice regarding biomedical waste:}

Higher percentage of correct response among doctors and nurses compared to technicians was consistent with the findings of Mathur et al among hospitals in Allahabad city. ${ }^{22}$ Present study also shows that regarding sharp collection, technicians gave maximum correct responses (53.7\%) compared to doctors (29.1\%). Regarding disease transmission, PPE, Vaccines and needle stick injury, doctors scored better than nurses and technicians. Nursing staffs scored better than doctors and technicians in collection and disposal related questions. Nursing staffs acquired highest overall knowledge score (15.52) than doctors (15.38) and technicians (10.56). Practice score was highest among doctors (7.35) than nursing staffs (4.58) and technicians (2.68). Doctors fared much better than nurses and technicians regarding vaccination and use of protective equipment.

Present study also showed that handlers gave maximum correct responses regarding colour coding of the bags and least correct responses on needle stick injury followed by vaccination and method of transportation. Mean knowledge score was more in general issues and less in transportation.Mean practice score was more in disposal and less in transportation. Knowledge and practice score of handlers showed significant correlation.

Study done by DeoDeepali et al in teaching hospitals shows knowledge regarding general information about biomedical waste was highest in medical staffs followed by paramedical and least in nonmedical staffs. But practical knowledge was highest in paramedical staff and least in nonmedical staff ${ }^{8}$. Saini et al had found that $80 \%$ of medical staff, about $60 \%$ of nursing staff and $20 \%$ of cleaning staffs had some knowledge in 600 bed super-specialty tertiary hospital in Delhi ${ }^{9}$. Waseem et al found similar differences in a teaching hospital in Sri Nagar, Jammu and Kashmir ${ }^{10}$. Kishore et al shows the majority of the 64 dentists working in a teaching hospital in New Delhi were not aware of proper hospital waste management. ${ }^{11}$ Yadavannavar $\mathrm{M} \mathrm{C}$ et al conducted a study to assess the knowledge, attitude, and practices (KAP) of the Shri BM Patil Medical College and Hospital, Bijapuramomg 180 non-teaching and 154 teaching staffs. The teaching staff of the hospital gave more correct responses $(97.4 \%)$ to questions on BMW management than the nonteaching staff $(80 \%)$. ${ }^{14}$,

\section{Occupational safety measures:}

Present study shows that 22(43.1\%) handlers used gloves whereas 3(5.9\%) used both gloves and mask. $28(55 \%)$ of biomedical handlers used none of the protective clothing. This finding almost corroborates findings of Sharma $S$ et $\mathrm{al}^{5}$. Sharma $\mathrm{S}$ et $\mathrm{al}^{5}$ found that in Sarojini Naidu Medical College, Agra, 17 handlers(31.48\%) 
reported that they used personal protective clothing during waste handling while the remaining 37 (68.52\%) stated that they did not use any type of personal protective clothing (PPC).

Present study also shows that post exposure prophylaxis were available in almost all health institutions except primary level health care settings. Post exposure prophylaxis was missing in primary health care institutions.

GaiRuoyan et al in their study in Shandong province, China shows that all tertiary and secondary hospitals and $63.6 \%$ of county hospitals provided protective measures ${ }^{24}$. Rasheeda $\mathrm{S}$ et al revealed in their study that two hospitals out of eight teaching hospitals in Karachi, Pakistan provided protective gears for handling dangerous waste to the waste handlers. ${ }^{25}$

Present study has found out that none of the observed health care institutions provided prophylactic immunisation (pertaining to biomedical waste) to the health care providers. In present study doctors, nurses, technicians and handlers sustained $7(9.2 \%), 27(35.5 \%), 9(11.8 \%)$ and 33(43.5\%) of total needle stick injuries in last six months respectively.

Out of total injury, only 8 injury( $10.5 \%$ ) reported to appropriate authority .Present study had shown that single injury reported by handler whereas Mathur et al had shown that none of the injuries were reported by the handlers and injury reporting was low even in other groups of the healthcare providers in hospitals in Allahabad city ${ }^{22}$.

Sharma $\mathrm{R}$ et al observed in their study that $37.04 \%$ o the health personnel had at least one needle stick injury within six months and none reported to higher authority 26.

Salelkar S et al conducted a cross-sectional study among health care workers at a tertiary care hospital in Goa to study the problem of needle stick injuries. Around 34.8\% (200/575) of the Health care workers had experienced a needle stick injury in the last one year ${ }^{4}$.

Sharma et al conducted cross-sectional study in a tertiary care hospital in Delhi among 322 resident doctors, interns, nursing staff, nursing students, and technicians. A large percentage $(79.5 \%)$ of Health care workers reported having had one or more needle stick injuries. ${ }^{22}$ Aslam M et al conducted a cross sectional, observational study in three public tertiary care hospitals of Karachi in 2007-08. A total of 417 health care workers (doctors, nurses, technicians) participated in the study. Estimated proportion of participants with history of at least one time Needle stick injury (NSI) was found in $66 \%$. None of them sought medical care. Almost $90 \%$ of them were not wearing gloves or taking any other protective measures at the time of injury. ${ }^{27}$ Askarian et $\mathrm{al}^{28}$ revealed in their study that in more than half of the hospitals $(60 \%)$, needle stick injuries are not reported and registered and no regulations for adequate management like post exposure prophylaxis are provided. According to Askarianet $\mathrm{al}^{28}$, lack of suitable and sufficient protective equipment, the lack of knowledge regarding the correct usage of equipment and the lack of knowledge regarding the benefits of using protective equipment exposes them to serious dangers.

Low reporting of injuries may be due to the fact that most of the health care providers are unaware about the formal system of reporting which should be established within all the health facilities. Worldwide the occurrence of needle stick injury was found to be quite common. Prevention of needle stick injury is an integral part of prevention programs in the work place, and training of HCWs (health care workers) regarding safety practices needs to be an indispensable ongoing activity at a hospital.

\section{Conclusion}

Most of hospitals had no provision for training regarding biomedical waste management. Training of all health care providers especially biomedical waste handlers should be emphasized. None of the health care institutions provide prophylactic vaccination (pertaining to biomedical waste) to the health care providers. There should be provision of prophylacticVaccination among all health care providers. Needle stick injury is an occupational hazard. It should be ensured that every injury is to be reported and documented in separate needle stick injury reporting register. Formal system of reporting should be established in all hospitals.

\section{References}

[1]. Glenn, Mc.R\&Garwal, R. (1999). Clinical waste in Developing Countries. An analysiswith a Case Study of India, and a Critique of the Basle TWG Guidelines.

[2]. MahammadiBaghaee,D.,Principles of Medical Waste Management 2000,1st Ed, 63-67.

[3]. Puro, V., De Carli, G., Petrosillo, N., Ippolito, G.,. Risk of exposure to blood borne infection for Italian healthcare workers,by job category and work area, Studio ItalianoRschioOccupazionale da HIV Group, Infect. Control Hosp. Epidemiol. 2001; 22 (4),206210 .

[4]. Salelkar S, Motghare DD, Kulkarni MS, Vaz FS. Study of needle stick injuries amonghealth care workers at a tertiary care hospital Indian J Public Health. 2010 ;54(1):18-20.

[5]. Sharma,S and Chuhan,S.V.Assessment of biomedical waste management in three apexgovernment hospitals of Agra.Journal of Environment Biology,29,159-162.

[6]. Akhtar A, Aslam M, Zafar MI. Unsafe injections: a potential source of HIV spread in Pakistan. IntConf AIDS 2004;15;11-16.

[7]. HP Chia,DKoh,RChong,JJeyaratnam.A study on needle-stick injuries among houseofficers in a major hospital. Singapore Med J 1994;35:41-43. 


\section{Knowledge And Practice Regarding Biomedical Waste In Different Levels Of Government Health ...}

[8]. A Study of Knowledge Regarding Biomedical Waste Management among Employees ofaTeachingHospitalinRuralArea.http://www.medwasteind.org/Journal /journa 15.1. pdf(accessed on 6.5.2011).

[9]. Saini,S.,Nagarajan,S.S and Sharma, R.K. Knowledge, attitude,practices of biomedicalwaste management amongst staff of tertiary level hospital in India. Journal of Academy of Hospital Administration,2005:17:25-30.

[10]. Waseem,Q.,Hassan,G.,Wani ,N.A.,Baba,S.,Kadri,A.M and Nazir,K. Awareness ofbiomedical waste management amongstaff of Government SMHS hospital,Srinagar-Atertiary level Hospital in Kahmir Valley,JK practitioner,14,60-6.

[11]. Kishore J,GoelP,SagarB,JoshiTK.Awareness about biomedical waste management andinfection control among dentist of a teaching hospital in New Delhi,India.IndiaJ.Dent Res2000;11:157-61.

[12]. Hospital Waste Management in the Union Territory Of Pondicherry http://www.pon.nic.in/citizen/science/ppcc-new/joe.pdf (accessible on 9.10.10)

[13]. Pandit NB, Mehta HK, Kartha GP, Choudhary SK Management of bio-medical waste:awareness and practices in a district of Gujarat. Indian J Public Health. 2005;49(4):245-7.

[14]. MC Yadavannavar, Aditya S Berad, and PB Jagirdar. Biomedical Waste Management: AStudy of Knowledge, Attitude, and Practices in a Tertiary Health Care Institution in Bijapur. Indian J Community Med. 2010 January; 35(1): 170-171.

[15]. Henry G and Heinke GW. 1996. Environmental Science and Engineering, 2nd Edition.Englewood, NJ: Pretence-Hall.

[16]. Abdulla, F., Qdais, H.A., Rabi, A. Site investigation on medical waste management practices in Northern Jordan. Waste Management 2008; 28: 450-458.

[17]. Hospital Waste Management Principles and Guidelines. Kanishka Publishers, New

Delhi.http://www.infibeam.com/Books/info/mohd-faisal-khan/hospital-waste management principlesguidelines/9788173916328.html.

[18]. Pital, G.V. \&Prkhrel, K. Biomedical solid waste management in an Indian hospital: acase study. Waste Management 2005; 25: 592599.

[19]. Bebcko, V, Kapek, J. \&Vins, O. Hospital waste treatment and disposal in the generaluniversity hospital - current situation and future challenges. SAGE Journal Online 2003;12:99-104.

[20]. Tsakona, M., Anagnostopoulou, E., Gidarakos, E., 2007. Medical waste management andtoxicity evaluation: a case study. Waste management 27, 912-920.

[21]. Mohee, R. Medical wastes characterisation in healthcare institutions in Mauritius. WasteManagement 25, 575-581.

[22]. MathurV,DwivediS,HassanMA,MishraRP.Knowledge, attitude, and practices aboutbiomedical waste management among healthcare personnel:A cross sectional study.Indian JCommunity Med 2011;36:143-5.

[23]. Saini,S.,Nagarajan,S.S and Sharma,R.K.Knowledge,attitude ,practices of biomedicalwaste management amongst staff of tertiary level hospital in India. Journal of Academy of Hospital Admimistration,2005:17:25-30.

[24]. GaiRuoyan,KuroiwaChusi, Xu Lingzhong,LiHuijuan,ZhouChengchao.Hospital .Medical waste management in ShadongProvince,China.Waste Management Research 2009:27:336-34.

[25]. Rasheed, S., Iqbal, S., Baig, L.A. Hospital waste management in the teaching hospitals ofKarachi. J. Pak. Med. Assoc;2005 :55 (5), 192-195.

[26]. Sharma R, SK, Verma A R, Singh S.Study of Prevalence and Response to Needle StickInjuries among Health Care Workers in a Tertiary Care Hospital in Delhi, India . Indian JCommunity Med. 2010; 35(1): 74-77.

[27]. Aslam M,TajT,AliA,MirzaW,AliH,DarMI,BadarN.Needle stick injuries among healthcare workers of public sector tertiary care hospitals of Karachi Coll Physicians SurgPak.2010;20(3);150-33.

[28]. Askarian M; Vakili M; and Kabir G. Results of a hospital waste survey in private hospitals in Fars province, Iran. Waste management 2004;24: 347-352.

Tables:

Table1.Distribution of respondents (doctors, nurses and technicians) according to knowledge on biomedical waste related issues. $(\mathrm{n}=315)$

\begin{tabular}{|c|c|c|c|}
\hline \multirow[t]{2}{*}{ Biomedical waste related issues } & \multicolumn{3}{|c|}{ Correct responses } \\
\hline & $\begin{array}{l}\text { Doctors }(\mathrm{n}=117) \\
\text { No. }(\%)\end{array}$ & $\begin{array}{l}\text { Nurses(n=159) } \\
\text { No. }(\%)\end{array}$ & $\begin{array}{c}\text { Technicians }(\mathrm{n}=39) \\
\text { No. }(\%)\end{array}$ \\
\hline \multicolumn{4}{|c|}{ Disease transmission, PPE, Vaccines (Maximum possible score $=6$ ) } \\
\hline $\begin{array}{l}\text { Diseases transmitted by biomedical } \\
\text { waste }\end{array}$ & $105(89.7)$ & 123(77.4) & $6(15.4)$ \\
\hline Personnel protective equipment (PPE) & $52(44.4)$ & $35(22)$ & $7(17.9)$ \\
\hline Vaccines & $100(85.5)$ & $122(76.7)$ & $15(38.5)$ \\
\hline Mean, range, $\mathrm{SD}$ & $5.18,3-6,0.78$ & $4.67,2-6,1.04$ & $3.31,1-5,0.89$ \\
\hline \multicolumn{4}{|c|}{ Collection(Maximum possible score $=8$ ) } \\
\hline Sharp & $34(29.1)$ & 54(34) & $21(53.8)$ \\
\hline Anatomical waste & $92(78.6)$ & $93(58.5)$ & $1(38.5)$ \\
\hline Infectious non sharp waste & $69(59)$ & $85(53.5)$ & $17(43.8)$ \\
\hline Pharmaceutical waste & $56(47.9)$ & $71(44.7)$ & $15(38.5)$ \\
\hline Mean, range, $\mathrm{SD}$ & $4.64,0-8,1.88$ & $4.88,1-8,1.73$ & $3.49,0-8,1.57$ \\
\hline \multicolumn{4}{|c|}{ Disposal(Maximum possible score $=6$ ) } \\
\hline Infectious non sharp waste & $49(41.9)$ & $83(52.2)$ & $15(38.5)$ \\
\hline Anatomical waste & $41(35)$ & $103(64.8)$ & $18(46.2)$ \\
\hline General waste & $76(65.0)$ & $79(49.7)$ & $17(43.6)$ \\
\hline Mean, range, $\mathrm{SD}$ & $3.23,0-6,1.57$ & $4.33,1-6,1.07$ & $2.56,0-6,1.94$ \\
\hline \multicolumn{4}{|c|}{ Needle stick injury related issues(Maximum possible score $=4$ ) } \\
\hline $\begin{array}{l}\text { Protective measures to be taken after } \\
\text { needle stick injury. }\end{array}$ & $43(36.8)$ & $48(30.2)$ & $6(15.4)$ \\
\hline Reporting & $78(66.8)$ & $70(44.4)$ & $5(12.8)$ \\
\hline Mean, range, $\mathrm{SD}$ & $2.33,0-4,1.06$ & $1.64,0-4,1.12$ & $1.21,0-4,1.08$ \\
\hline \multicolumn{4}{|c|}{ Overall (Maximum possible score 24) } \\
\hline Overall Mean, range, SD & $15.38,7-23,3.09$ & $15.52,10-21,2.45$ & $10.56,3-17,3.25$ \\
\hline
\end{tabular}




\section{Knowledge And Practice Regarding Biomedical Waste In Different Levels Of Government Health ...}

Table 2. Practice score obtained by the doctors, nurses and technicians. $(n=215)$

\begin{tabular}{|l|c|c|c|}
\hline Scores & Doctors(n=37) & Nurses(n=159) & Technicians(n=39) \\
\hline \multicolumn{4}{|c|}{ PPE, Vaccines (Maximum possible score=8) } \\
\hline Mean score & 4.83 & 2.59 & 1.00 \\
\hline Range & $1-8$ & $0-7$ & $0-6$ \\
\hline Standard deviation & 1.708 & 1.713 & 1.649 \\
\hline \multicolumn{4}{|c|}{ Collection(Maximum possible score=2) } \\
\hline Mean score & 1.33 & 0.97 & 1.08 \\
\hline Range & $0-2$ & 0.812 & $0-2$ \\
\hline Standard deviation & 0.797 & $0-2$ & 0.764 \\
\hline \multicolumn{5}{|c|}{ Disposal(Maximum possible score=2) } \\
\hline Mean score & 1.20 & 1.02 & 0.60 \\
\hline Range & 0.648 & 0.419 & 0.591 \\
\hline Standard deviation & $0-2$ & $0-2$ & $0-2$ \\
\hline \multicolumn{5}{|c|}{ Total practice score(Maximum possible score=12) } \\
\hline Mean score & 7.35 & 4.58 & 2.68 \\
\hline Range & $3-11$ & $1-10$ & $1-8$ \\
\hline Standard deviation & 2.179 & 1.905 & 1.607 \\
\hline
\end{tabular}

Table 3.Statistical comparison of knowledge and practice score obtained by doctors, nurses

\begin{tabular}{|c|c|c|c|c|}
\hline \multirow[t]{2}{*}{ Topics } & \multirow[t]{2}{*}{ ANOVA } & \multicolumn{3}{|c|}{ TUCKEY KRAMER TEST } \\
\hline & & Mean difference of scores & $\mathrm{p}$ values & \\
\hline \multicolumn{5}{|c|}{ Knowledge score } \\
\hline \multirow{2}{*}{$\begin{array}{l}\text { Disease transmission, } \\
\text { PPE, Vaccines }\end{array}$} & $\mathrm{F}=58.72$ & Doctors $=\mathbf{0 . 5 0 7}$ & Doctors-Nurses & 0.000 \\
\hline & $\begin{array}{l}\mathrm{p}=0.000 \\
\mathrm{df}=2\end{array}$ & $\begin{array}{l}\text { Nurse }=0^{\prime} \\
\end{array}$ & Nurses- Technicians & 0.000 \\
\hline \multirow{3}{*}{ Collection } & $\mathrm{F}=9.718$ & Doctors $=\mathbf{- 0 . 2 3 9}$ & Doctors- Nurses & 0.508 \\
\hline & $\mathrm{p}=0.000$ & Nurse $=\mathbf{0}^{\prime}$ & Nurses- Technicians & 0.001 \\
\hline & $\mathrm{df}=2$ & Technicians $=\mathbf{- 1 . 3 9 3}$ & Doctors- Technicians & 0.000 \\
\hline \multirow[t]{3}{*}{ Disposal } & $\mathrm{F}=170.449$ & Doctors $=-\mathbf{- 1 . 1 0 3}$ & Doctors-Nurses & 0.000 \\
\hline & $\mathrm{p}=0.000$ & Nurses $=\mathbf{0}^{\prime}$ & Nurses-Technicians & 0.000 \\
\hline & $\mathrm{df}=2$ & Technicians= $\mathbf{- 1 . 7 6 9}$ & Doctors-Technicians & 0.258 \\
\hline \multirow[t]{3}{*}{ Needle stick injury } & $\mathrm{F}=21.375$ & Doctors $=\mathbf{0 . 6 9 8}^{\prime}$ & Doctors-Nurses & 0.000 \\
\hline & $\mathrm{p}=0.000$ & Nurses $=-\mathbf{0}^{\prime}$ & Nurses-Technicians & 0.072 \\
\hline & $\mathrm{df}=2$ & Technicians $=\mathbf{0 . 4 3 0}^{-}$ & Doctors-Technicians & 0.000 \\
\hline \multirow[t]{3}{*}{ Total score } & $\mathrm{F}=52.090$ & Doctors $=-\mathbf{1 . 3 7 ^ { \prime }}$ & Doctors-Nurses & 0.915 \\
\hline & $\mathrm{p}=0.000$ & Nurses $=\mathbf{0}^{-}$ & Nurses-Technicians & 0.000 \\
\hline & $\mathrm{df}=2$ & Technicians $=\mathbf{- ~ 4 . 9 5 8}$ & Doctors-Technicians & 0.000 \\
\hline \multicolumn{5}{|c|}{ Practice score } \\
\hline \multirow[t]{3}{*}{ PPE, Vaccines } & $\mathrm{F}=41.802$ & Doctors $=2.051^{\prime}$ & Doctors-Nurses & 0.000 \\
\hline & $\mathrm{p}=0.000$ & Nurses $=\mathbf{0}^{\prime}$ & Nurses- Technicians & 0.000 \\
\hline & $\mathrm{df}=2$ & Technicians $=\mathbf{- 1 . 5 4 3}$ & Doctors-Technicians & 0.000 \\
\hline \multirow{3}{*}{ Collection } & $\mathrm{F}=1.756$ & Doctors $=\mathbf{0 . 3 4 5}^{\prime}$ & Doctors-Nurses & 0.115 \\
\hline & $\mathrm{p}=0.017$ & Nurses $=\mathbf{0}^{\prime}$ & Nurses- Technicians & 0.729 \\
\hline & $\mathrm{df}=2$ & Technicians $=\mathbf{0 . 0 6 3}$ & Doctors-Technicians & 0.580 \\
\hline \multirow{3}{*}{ Disposal } & & Doctors $=\mathbf{0 . 1 1 0}$ & Doctors-Nurses & 0.437 \\
\hline & $\mathrm{p}=0.000$ & Nurses $=\mathbf{0}^{\prime}$ & Nurses-Technicians & 0.000 \\
\hline & $\mathrm{df}=2$ & Technicians= - 458.' & Doctors-Technicians & 0.000 \\
\hline \multirow{3}{*}{ Total score } & & & & 0.000 \\
\hline & $\mathrm{p}=0.000$ & Nurses=0 $0^{\prime}$ & Nurses-Technicians & 0.000 \\
\hline & $\mathrm{df}=2$ & Technicians $=\mathbf{- 1 . 8 9 3}$ & Doctors-Technicians & 0.000 \\
\hline
\end{tabular}

Table4.Distribution of biomedical waste disposal handlers according to knowledge of biomedical waste management. $(n=51)$

\begin{tabular}{|c|c|c|c|c|}
\hline \multirow{2}{*}{$\begin{array}{l}\text { Biomedical waste management } \\
\text { related issues }\end{array}$} & \multirow{2}{*}{$\begin{array}{c}\text { Correct responses } \\
\text { No. }(\%)\end{array}$} & \multicolumn{3}{|c|}{ Knowledge score } \\
\hline & & Mean score & Range & Standard deviation \\
\hline \multicolumn{5}{|c|}{ Colour coding, Personnel protective equipment and vaccination needle stick injury..(Maximum possible score=6) } \\
\hline $\begin{array}{l}\text { Colour coding bags } \\
\text { Personnel protective equipment } \\
\text { Vaccination }\end{array}$ & $\begin{array}{c}19(37.3) \\
6(11.8) \\
4(7.8)\end{array}$ & 3.14 & $1-6$ & 1.0 \\
\hline \multicolumn{5}{|c|}{ Needle stick injury related issues(Maximum possible score $=2$ ) } \\
\hline Needle stick injury related issues & $2(3.9)$ & 0.92 & $0-2$ & 0.392 \\
\hline \multicolumn{5}{|c|}{ Collection(Maximum possible score $=6$ ) } \\
\hline $\begin{array}{l}\text { Needles, slides } \\
\text { Placenta } \\
\text { Catheter, plastics }\end{array}$ & $\begin{array}{c}6(11.8) \\
16(31.4) \\
18(35.3) \\
\end{array}$ & 2.37 & $0-5$ & 1.428 \\
\hline \multicolumn{5}{|c|}{ Transportation(Maximum possible score $=2$ ) } \\
\hline Method of transportation & $5(9.8)$ & 0.31 & $0-2$ & 0.648 \\
\hline
\end{tabular}


Knowledge And Practice Regarding Biomedical Waste In Different Levels Of Government Health ...

\begin{tabular}{|l|l|c|c|c|}
\hline $\begin{array}{l}\text { Placenta } \\
\text { Paper }\end{array}$ & $\begin{array}{l}14(27.5) \\
11(21.6)\end{array}$ & 1.33 & $0-3$ & 0.816 \\
\hline \multicolumn{2}{|l|}{ Total score(Maximum possible score=20) } & 8.08 & $2-11$ & 2.077 \\
\hline
\end{tabular}

Table 5.Practice score obtained by the biomedical waste handlers. $(\mathrm{n}=51)$

\begin{tabular}{|l|c|c|c|}
\hline \multirow{2}{*}{ Items } & \multicolumn{2}{|c|}{ Practice score } \\
\cline { 2 - 4 } & Mean score & Range & Standard deviation \\
\hline $\begin{array}{l}\text { Personnel protective equipment and vaccination } \\
\text {,training(Maximum possible score=8) }\end{array}$ & 0.63 & $0-4$ & 0.48 \\
\hline Transportation(Maximum possible score=2) & 0.18 & $0-2$ & 0.518 \\
\hline Disposal(Maximum possible score=2) & 0.69 & $0-2$ & 0.836 \\
\hline Total score(Maximum possible score=12) & 2.08 & $0-8$ & 1.885 \\
\hline
\end{tabular}

